\title{
Corrosion behavior of cold sprayed titanium coatings and free standing deposits
}

\author{
T. Hussain ${ }^{1}$, D. G. McCartney ${ }^{1}$, P. H. Shipway ${ }^{1}$, T. Marrocco ${ }^{2}$ \\ ${ }^{1}$ Division of Materials, Mechanics and Structures, Faculty of Engineering, University of \\ Nottingham, Nottingham, UK \\ ${ }^{2}$ The Welding Institute (TWI) Ltd, Cambridge, UK \\ Keywords: Cold spray, titanium, corrosion, heat treatment, porosity
}

\begin{abstract}
Cold gas dynamic spraying can be used to deposit oxygen sensitive materials, such as titanium, without significant chemical degradation of the powder. The process is thus believed to have potential for the deposition of corrosion resistant barrier coatings. However, to be effective, a barrier coating must not allow ingress of a corrosive liquid and hence must not have interconnected porosity. This study investigated the effects of porosity on the corrosion behavior of cold sprayed titanium coatings onto carbon steel and also of free standing deposits. For comparative purposes, a set of free standing deposits was also vacuum heat treated to further decrease porosity levels below those in the as-sprayed condition. Microstructures were examined by optical and scanning electron microscopy. Mercury intrusion porosimetry (MIP) was used to characterize the interconnected porosity over a size range of micrometers to nanometers. Open circuit potential (OCP)
\end{abstract}


measurements and potentiodynamic polarization scans in $3.5 \mathrm{wt} . \% \mathrm{NaCl}$ were used to evaluate the corrosion performance.

The MIP results showed that in cold sprayed deposits a significant proportion of the porosity was sub-micron and so could not be reliably measured by optical microscope based image analysis. In the case of free standing deposits, a reduction in interconnected porosity resulted in a lower corrosion current density, a lower passive current density and an increase in open circuit potential closer to that of bulk titanium. For the lowest porosity level, $\sim 1.8 \%$ achieved following vacuum heat treatment, the passive current density was identical to that of bulk titanium. However, electrochemical measurements of the coatings showed significant substrate influence when the interconnected porosity of the coating was 11.3 vol. \% but a decreased substrate influence with a porosity level of 5.9 vol. \%. In the latter case the OCP was still around $250 \mathrm{mV}$ below that of bulk Ti. Salt spray tests confirmed these electrochemical findings and showed the formation of surface corrosion products following 24 hours exposure. 


\section{Introduction}

Titanium metal has excellent corrosion resistance in a number of aqueous media including salt water due to the presence of a tenacious oxide film [1] and so titanium and its alloys have been used in a number of situations to protect steel structures and components from attack [2]. However, deposition of protective coatings of titanium by thermal spraying processes is problematic due to the fact that titanium reacts readily with oxygen to form $\mathrm{TiO}_{2}$ at elevated temperature. Hence the resultant coatings contain features such as oxide inclusions and interconnected pores which prevent the realization of the protective capabilities of titanium as a barrier coating. Indeed, a barrier coating needs to be entirely free from interconnected porosity to provide reliable corrosion protection. In the case of thermally sprayed coatings, a number of studies to evaluate corrosion behavior have been performed. For example, Zhao et al. [3] investigated the behavior of titanium which was arc sprayed in air and found that oxides and nitrides present in the coating degraded the corrosion resistance. Also a study by Ishikawa et al. [4] found that flame sprayed titanium coatings did not provide corrosion protection due to the high level of coating porosity. To avoid the problem of the reaction of titanium with the environment vacuum plasma and shrouded air plasma spraying have both been employed to deposit coatings $[5,6]$. However, a corrosion study of shrouded plasma sprayed titanium coatings in salt solution by Kinos et al. [6] using potentiodynamic methods indicated that coating porosity significantly increased the corrosion rate compared to bulk titanium. More recently Kuroda and co-workers $[7,8]$ have reported the development of a modified high velocity oxy-fuel (HVOF) process 
termed warm spraying which is reportedly capable of producing titanium coatings with porosity levels less than $1 \%$. However, the corrosion rates of these warm sprayed coatings were also higher than bulk titanium because of the presence of interconnected porosity.

Evidently, there is considerable interest in developing corrosion resistant titanium coatings as barrier layers and so more recently much attention has focused on using the cold spray process to deposit titanium coatings. As an emerging technology, cold spray is being used increasingly to spray materials at high deposition rates in which significant particle melting is avoided [9-11]. It has been found that metals such as copper can be deposited to produce coatings free from porosity as determined by open circuit potential tests [12]. Hence, there is now a growing interest in cold spray deposition of titanium with a significant body of work on titanium coatings and the effect of process parameters such as powder type, gas pressure, temperature and type of gas on deposit characteristics including porosity [11, 13-19]. A wide range of porosity values in cold sprayed titanium coatings has been reported in literature (24$0.5 \%)$, most of which was measured using image analysis techniques $[11,15-17$, 19]. The porosity of the coatings reported in the literature depends on the process parameters, type of process gas and limitations of the spraying system. In general, higher in-flight particle velocity achieved from helium as a process gas resulted in a denser titanium coatings [18]. However, corrosion studies of cold sprayed titanium coatings are much less extensive. Wang et al. $[2,11]$ showed that the corrosion rate of coated steel substrates in salt solution was higher than bulk titanium due to interconnected porosity. However, there is no published data on the corrosion behavior of cold sprayed free standing titanium deposits to the knowledge of the 
authors. Furthermore, there is little attention given in the literature to quantifying the porosity of cold sprayed titanium by techniques other than image analysis of micrographs and in relating the porosity to corrosion behaviour in aqueous solutions.

Therefore the aim of this study was to quantify and characterize the porosity of cold sprayed titanium deposits by mercury intrusion porosimetry and to investigate the role of porosity in the corrosion behavior in salt water of both free standing titanium deposits and coatings on a steel substrate. Moreover, for comparative purposes, free standing deposits were heat treated to reduce their porosity and the effect of this was also evaluated.

\section{Experimental Methods}

\subsection{Materials}

Commercially pure inert gas atomized titanium powder (LPW, Cheshire, UK) was used to produce the deposits. The feedstock powder was spherical in shape with only a very small fraction exhibiting satellite particles (Figure 1a). The particle size analysis measured by laser diffractometry (Malvern Mastersizer S, Malvern Instruments, Worcestershire, UK) showed that $90 \%$ of the particles were in the supplier specified size range of $-30+10 \mu \mathrm{m}$ with approximately 10 vol. \% below 10 $\mu \mathrm{m}$ (Figure 1b). The titanium powder was deposited onto carbon steel samples (0.037 wt.\% C, 0.17 wt. $\% \mathrm{Mn}, 0.01$ wt. $\% \quad \mathrm{P}, 0.02$ wt. $\% \mathrm{~S}$ and balance $\mathrm{Fe}$ ) of dimensions $40 \times 25 \times 2 \mathrm{~mm}$. 


\subsection{Cold gas spraying of titanium}

The coatings and free standing deposits were prepared with a $\mathrm{CGT}^{\mathrm{TM}}$ Kinetiks ${ }^{\circledR}$ 4000/47 system at TWI Ltd. The de Laval nozzle had a length of $170 \mathrm{~mm}$ and a throat diameter of $2.7 \mathrm{~mm}$ with an area expansion ratio of $\sim 6.5$. The system utilized heated nitrogen gas both for the primary accelerating gas and the powder carrier gas. A high pressure powder feeder (CGT) was used during the cold spraying process with a carrier gas flow-rate of $3.7 \mathrm{~m}^{3} / \mathrm{h}$ and powder feeder wheel speed of $3.5 \mathrm{rpm}$ giving an approximate powder feedrate of $1.6 \mathrm{~kg} / \mathrm{h}$. The nozzle-substrate standoff distance for all the spray conditions was fixed at $40 \mathrm{~mm}$.

The deposition conditions for the samples are presented in Table 1. The carbon steel substrates sprayed at $600{ }^{\circ} \mathrm{C}$ were grit blasted in a conventional manual grit blasting cabinet at 2.75 bar with a grit size of $\sim 125 \mu \mathrm{m}$. It was not possible to produce a well bonded coating onto a cabinet grit blasted carbon steel surface at the higher gas temperature. Hence, a more controlled grit blasting process using the cold spraying gun, which was mounted on a six axis robot, was used at 25 bar with a grit size of $45-90 \mu \mathrm{m}$. The substrates were cleaned ultrasonically in a bath of acetone for 15 minutes, rinsed with methyl alcohol and dried using compressed air immediately prior to spraying. Substrates were then clamped in a vice and the gun, mounted on the six axis robot manipulator scanned the surface of the samples at $600 \mathrm{~mm} / \mathrm{s}$. The increment of the scan was set at $0.75 \mathrm{~mm}$. The deposits were built up using four passes of the gun. 
A free standing deposit was obtained by carefully delaminating a coating from the steel substrate. The deposit sprayed at $600^{\circ} \mathrm{C}$ gas temperature is referred to as free standing deposit FS1 and when coated onto carbon steel as C1. The deposit sprayed at $800{ }^{\circ} \mathrm{C}$ gas temperature is referred to as free standing deposit FS2, and when coated onto carbon steel as C2 in this paper.

\subsection{Post spray heat treatment}

Free standing deposits were sealed in a quartz tube under a vacuum of $10^{-4}$ Torr to avoid oxidation. The heat treatment was performed at $1050{ }^{\circ} \mathrm{C}$ for 60 minutes in a rapid heating furnace (Carbolite, Sheffield, UK) at a heating rate of $50 \mathrm{~K} / \mathrm{min}$. The heat treatment temperature was $150 \mathrm{~K}$ above the $\beta$-transus temperature of commercially pure titanium. Following heat treatment, the quartz tube was air cooled to room temperature.

\subsection{Corrosion tests}

Potentiodynamic electrochemical tests of free standing titanium deposits and coatings were carried out using an ACM Gill 8 sequencer (ACM Instruments, Cumbria, UK) in a standard 3 electrode cell. A platinum metal strip of $100 \mathrm{~mm}^{2}$ was used as an auxiliary electrode and the cell temperature was maintained at $30 \pm 1{ }^{\circ} \mathrm{C}$ using a water bath. All the potentials were measured with respect to an $\mathrm{Ag} / \mathrm{AgCl}$ secondary electrode. The samples were tested in a solution of $3.5 \mathrm{wt} . \% \mathrm{NaCl}$ in deionized water and a flow of nitrogen gas was maintained at $0.1 \mathrm{~L} / \mathrm{min}$ during the full duration of the experiments. Nitrogen flowed through the solution for 30 minutes before the start of the test to stabilize the cell. 
The substrate side of the free standing samples was lightly ground to remove any residual steel. The as-sprayed top surface of each sample was ground to P1200 grit finish to remove the top porous layer. The samples were painted with a stopping off lacquer to expose only $100 \mathrm{~mm}^{2}$ for testing. Finally, the sample surfaces were degreased using methanol, cleaned with deionized water and dried immediately before immersion.

The open circuit potential (OCP) of the specimens was measured during the first 60 minutes of immersion before starting the potentiodynamic scans. To conduct the polarization scans the samples were first lowered to a potential of $200 \mathrm{mV}$ below the open circuit potential and then scanned at a rate of $20 \mathrm{mV} / \mathrm{min}$ in the anodic direction. The scans were stopped when the potential of the samples reached an upper limit of $1800 \mathrm{mV}$ above the rest potential, Ecorr. The intersection of the anodic and cathodic linear extrapolations at the rest potential of potentiodynamic polarization scans (Tafel extrapolation) was taken as the corrosion current density, Icorr. The passive current density, Ipp was taken as the current density of the passive region from the potentiodynamic polarization scans.

Reproducibility of the corrosion measurements was evaluated by running repeat tests on both free standing deposits and coatings. Three separate samples of free standing deposit FS1 and three samples of coating C2 were tested under the same conditions. The variations in measured values of the three free standing FS1 deposits were as follows: OCP $\pm 30 \mathrm{mV}$; Ecorr $\pm 2.5 \mathrm{mV}$; Ipp $\pm 0.005 \mathrm{~mA} / \mathrm{cm}^{2}$ and Icorr \pm 0.0005 $\mathrm{mA} / \mathrm{cm}^{2}$. The variations in measured values of the three $\mathrm{C} 2$ coatings were as follows: OCP $\pm 13 \mathrm{mV}$; Ecorr $\pm 30 \mathrm{mV}$; Ipp $\pm 0.025 \mathrm{~mA} / \mathrm{cm}^{2}$ and Icorr $\pm 0.0005 \mathrm{~mA} / \mathrm{cm}^{2}$. 
These values are well within the typical range of experimental in electrochemical studies of this type. Therefore graphs of typical open circuit potential changes with time and potentiodynamic polarization scans for each sample are presented in this study.

Salt spray (fog) tests were performed for 24 hours on coatings sprayed onto carbon steel with a dimension of $25 \times 20 \times 2.5 \mathrm{~mm}$ using a 5 wt. \% $\mathrm{NaCl}$ solution. The back and the sides of the samples were covered with a red stopping off lacquer (toluene) to avoid any galvanic corrosion and only the top of the coating surface was exposed.

\subsection{Sample preparation and characterization}

Coating cross-sections were prepared by cutting with a diamond slitting wheel. The samples were sequentially ground using SiC paper and polished with 10:1 colloidal $(0.1 \mu \mathrm{m})$ silica suspension and $\mathrm{H}_{2} \mathrm{O}_{2}$ on a MD-Chem cloth (Struers UK). Samples were examined by both optical and scanning electron microscopy. A FEI XL30 (FEI Europe, Eindhoven, The Netherlands) scanning electron microscope (SEM) operating at $20 \mathrm{keV}$ was employed to examine the microstructure of the coatings using secondary electron (SE) imaging. The coatings were lightly etched in Krolls etchant ( $2 \% \mathrm{HF}, 5 \% \mathrm{HNO}_{3}$ and $95 \% \mathrm{H}_{2} \mathrm{O}$ ) for 15 seconds prior to examination in the microscope. The etching time needs to be kept constant as the etch attacks the microstructure and affects the visible features. The morphology of the powders and deposit top surfaces was also examined in the SEM using SE imaging. 
The porosity of the free standing deposits was measured using a mercury intrusion porosimeter (Autopore IV, Micromeritics, Norcross, GA, USA). There are two ports in the porosimeter: a low pressure port and a high pressure port. The low pressure port evacuates any air trapped inside the sample and then fills it with mercury at 0.14 $\mathrm{MPa}$. The sample is then transferred to the high pressure port where the mercury infiltrates the sample at pressures up to $415 \mathrm{MPa}$. Free standing deposits of dimension $10 \times 8 \times 1 \mathrm{~mm}$ were used for the mercury intrusion tests. Mercury intrusion porosimetry (MIP) can only be used to measure the open porosity which is connected to the surface of the deposits. Results are presented in the form of intrusion volume of mercury per gram of sample versus pressure where pore diameter is then calculated from the pressure values using Washburn's equation.

$\mathrm{D}=-\left(\frac{1}{P}\right) 4 \gamma \cos \varphi \quad$ equation 1

Where $\mathrm{D}$ is the pore diameter, $\mathrm{P}$ is the applied pressure, $\mathrm{Y}$ is the surface tension of mercury, and $\varphi$ is the contact angle. Total mercury intrusion $(\mathrm{mL} / \mathrm{g})$ values were converted to volume percentages of porosity of the deposits assuming that the density of titanium is $4500 \mathrm{~kg} / \mathrm{m}^{3}$. 


\section{Results}

\subsection{Microstructure and corrosion behavior of free standing deposits}

\subsubsection{Microstructure of cold sprayed titanium}

The microstructure (unetched) of cold sprayed titanium sprayed at $600{ }^{\circ} \mathrm{C}(\mathrm{C} 1)$ and $800{ }^{\circ} \mathrm{C}(\mathrm{C} 2)$ process gas temperatures onto carbon steel are shown in Figures 2 (a, b). The microstructure of the coating $C 1$ shows a porous top layer of $150 \mu \mathrm{m}$ and a lower porosity bottom layer. The top porous layer is not as obvious in coating C2 which was sprayed at a higher process gas temperature. This porous top layer formation in cold sprayed titanium coating is similar to that reported previously by other researchers $[13,14]$. The coatings do not show cracking or any delamination along the coating-substrate interface, but do show the presence of fractured alumina (darker contrast) from the surface preparation methods. The thickness of coating C1 was $900 \mu \mathrm{m}$, whereas the thickness of coating C2 was $550 \mu \mathrm{m}$. This difference in coating thickness could be due to irregularities in powder feeding, although the nominal powder feed rate and gun traverse speed in both cases were the same.

Figures 2 (c, d) show higher magnification images of etched as-sprayed free standing deposits FS1 and FS2 taken from near the mid-plane of the coating. The microstructure is made up of a mixture of different sized particles, and voids are observed in both coatings at the interparticle boundaries. These voids are not visible in the unetched sample and result from loss of particles due to the attack of the particle boundaries by the etchant. In a number of places the initial spherical shape 
of the titanium powder particle was retained which indicates a lower degree of plastic deformation in FS1. These areas are marked with circles in Figure 2c. However, in Figure 2d more extreme particle deformation is apparent (see circled regions). Because etching attacks the particle boundaries a prolonged etching results in losing particles from the deposits, so the "apparent" porosity depends on the duration of etching. Also in unetched samples smearing of Ti during sample preparation can lead to an underestimate of porosity. Optical microscopy is thus an unreliable way of determining overall porosity in cold sprayed titanium coatings [20]. This is why mercury intrusion porosimetry was used to quantify the "actual" porosity in this study.

The free standing deposits FS1 and FS2, after heat treatment at $1050^{\circ} \mathrm{C}$, are shown in Figures $2(\mathbf{e}, \mathbf{f})$ following etching. Most of the interparticle pores in FS2 deposit were eliminated following heat treatment due to recrystallization and grain growth at higher temperature, but a number of isolated regions of defects were still present in FS1. X-ray diffraction (XRD) analysis of both as-sprayed and heat treated deposits showed the presence of only $\alpha-\mathrm{Ti}$. No secondary phases were present within the limits of XRD sensitivity (i.e. 1-2 vol. \%). Figure 3 shows higher magnification secondary electron (SE) images of the deposits before and after heat treatment. The pores in as-sprayed FS1 and FS2 deposits (Figures $\mathbf{3 a}, \mathbf{b}$ ) are mostly at the interparticle boundaries and the gas atomized titanium powder particles show little evidence for pores within them. The heat treated free standing FS1 deposit shows a reduction of interparticle voids and spheriodization of pores (Figure 3c). Interparticle boundaries, nearly free from defects, were observed following heat 
treatment of FS2 and formation of metallurgical bonds at the interparticle splats (boxed region in Figure 3d).

Figures $4(\mathbf{a}, \mathbf{b})$ show the as-sprayed top surface view of free standing deposits FS1 and FS2. The top surface of free standing deposit FS1 shows a higher surface roughness which corresponds to the top porous layer in the cross-sectional image in Figure 2a. Top surface of FS1 had a surface roughness ( $R a)$ value of $8 \mu \mathrm{m}$ and top surface of FS2 had a surface roughness (Ra) value of $4 \mu \mathrm{m}$. Figures $4(\mathbf{c}, \mathbf{d})$ show higher magnification images of free standing deposits FS1 and FS2. FS1 deposit shows smaller titanium particles deposited onto larger titanium particles, and in some places, on larger particles, there is evidence of sliding and rebounding after impact. Rupture of the bonding of a titanium particle is also observed in the image, marked with boxes in the Figure 4c. In Figure 4d, the shear lips of titanium particles where the plastic flow of titanium occurred following the occurrence of adiabatic shear instability phenomena are marked with arrows [21]. There is no evidence for re-bounding or ruptured bonding in this figure. Lower magnification images of heat treated top surfaces of free standing titanium deposits FS1 and FS2 are shown in Figures $4(\mathbf{e}, \mathbf{f})$. The heat treated deposits show new grain growth and elimination of previous particle boundaries. Heat treated free standing FS1 (Figure 4e) shows larger intergrain voids compared to heat treated FS2 (Figure 4f). Figures $4(\mathbf{g}, \mathbf{h})$ show higher magnification images of heat treated free standing deposits FS1 and FS2. In both deposits, grain growth following heat treatment shows a reduction of pores with the formation of faceted grain boundaries. 


\subsubsection{Porosity of free standing deposits}

Mercury intrusion porosimetry was used to characterize the open pore size distribution of the FS1 and FS2 deposits, before and after heat treatment. Figure 5a shows the incremental mercury intrusion with respect to pore sizes of FS1 and FS2 deposits before and after heat treatment. The as-sprayed FS1 deposit has a pore size distribution of $0.3-8 \mu \mathrm{m}$. Heat treatment of FS1 altered the pore size range to $0.6-2.5 \mu \mathrm{m}$. The majority of the pores in the FS2 deposit were in the size range of $0.18-1.6 \mu \mathrm{m}$ with a smaller number of very fine pores of size $0.003-0.004 \mu \mathrm{m}$. Heat treatment of FS2 showed a virtual complete elimination of larger pores and resulted in formation of very small pores of $0.006 \mu \mathrm{m}$ to $0.013 \mu \mathrm{m}$.

Figure 5b shows the cumulative intrusion of mercury per gram of sample versus pore diameter. The cumulative intrusion for the as-sprayed FS1 deposit was 0.025 $\mathrm{mL} / \mathrm{g}$ with a sharp increase of cumulative intrusion curve at $2-3 \mu \mathrm{m}$ pore sizes. The larger pores are filled up with mercury at lower pressure and smaller pores are infiltrated at higher pressure. Following heat treatment of FS1, the total amount of intruded mercury decreased to $0.01 \mathrm{~mL} / \mathrm{g}$, i.e. decrease in the total pore volume. The cumulative intrusion of as-sprayed FS2 deposit was $0.013 \mathrm{~mL} / \mathrm{g}$, which is half the amount compared to as-sprayed FS1 deposit $(0.025 \mathrm{~mL} / \mathrm{g})$. The slope of the FS2 cumulative intrusion curve sharply increases at the pore sizes of 1-2 $\mu \mathrm{m}$. After heat treatment, FS2 deposit exhibited a cumulative intrusion of only $0.004 \mathrm{~mL} / \mathrm{g}$. The equivalent volume percentages of porosity from mercury intrusion tests are shown in Table 2. The last two columns of the table show the volume percentages of porosity of the deposits corresponding to pore sizes below and above $1 \mu \mathrm{m}$. In as-sprayed and heat treated FS1, the pore sizes above $1 \mu \mathrm{m}$ accounted for the majority of the 
porosity. However, in the as-sprayed and heat treated FS2 deposit, the pores smaller than $1 \mu \mathrm{m}$ accounted for the majority of the porosity. Evidently optical microscopy can only detect pores of diameter approximately $\geq 1 \mu \mathrm{m}$ and so will not detect these very fine pores.

\subsubsection{Open circuit potential and potentiodynamic polarization of free standing deposits}

Figure 6a shows the typical open circuit potential (OCP) measurements of bulk titanium, as-sprayed free standing deposit FS1, and heat treated free standing deposit $\mathrm{FS} 1$ in $3.5 \% \mathrm{NaCl}$ solution for 3600 seconds. The bulk titanium reached a steady state OCP of $-220 \mathrm{mV}$ with respect to $\mathrm{Ag} / \mathrm{AgCl}$ electrode within a few minutes of immersion. Both the open circuit potentials of as-sprayed and heat treated free standing FS1 deposits were $\sim-530 \mathrm{mV}(\mathrm{Ag} / \mathrm{AgCl})$.

Figure $\mathbf{6 b}$ shows typical potentiodynamic polarization scans of the bulk titanium, assprayed free standing deposit FS1, and heat treated free standing FS1 deposit. The scan of bulk titanium showed typical active-passive behavior of a passivating metal. Bulk titanium had a passivation range of $250 \mathrm{mV}$ to $1250 \mathrm{mV}$, after which it showed trans-passive behavior. The passive current density (Ipp) of bulk titanium was 0.005 $\mathrm{mA} / \mathrm{cm}^{2}$. The as-sprayed free standing FS1 deposit showed "passive-like" behavior from $70 \mathrm{mV}$ to $1250 \mathrm{mV}$, during which the current density increased from 0.017 $\mathrm{mA} / \mathrm{cm}^{2}$ to $0.13 \mathrm{~mA} / \mathrm{cm}^{2}$. It also reached the limiting voltage value during the potentiodynamic polarization scan before the onset of trans-passive behavior. The heat treatment of free standing deposit FS1 resulted in a decrease of passive current 
density to $0.007 \mathrm{~mA} / \mathrm{cm}^{2}$. The Ecorr of both the as-sprayed deposit FS1 and heat treated deposit FS1 lie around $\sim 580 \mathrm{mV}$, but the Icorr value showed a decrease of two orders of magnitude after the heat treatment. The Ecorr and Icorr values of all the samples are shown in Table 3.

Open circuit potential measurements of as-sprayed and heat treated FS2 in $3.5 \mathrm{wt}$. $\% \mathrm{NaCl}$ solution are shown in Figure $\mathbf{7 a}$. The open circuit potential of as-sprayed FS2 was $-510 \mathrm{mV}$ and that of heat treated FS2 was $-365 \mathrm{mV}$. The heat treatment of free standing deposit FS2 resulted in a shift of $\sim 145 \mathrm{mV}$ in the more positive direction, towards the bulk titanium. This is a significant difference from the behavior of heat treated FS1.

Figure 7b shows the potentiodynamic polarization of as-sprayed and heat treated FS2 deposit. These showed similar passive current density $\left(0.005 \mathrm{~mA} / \mathrm{cm}^{2}\right)$ to bulk titanium. The Ecorr values of the as-sprayed and heat treated FS2 deposits showed similar trends to OCP measurements. The Icorr value of the heat treated FS2 deposit reduced to $3 \times 10^{-5} \mathrm{~mA} / \mathrm{cm}^{2}$ from $2 \times 10^{-4} \mathrm{~mA} / \mathrm{cm}^{2}$ following heat treatment.

\subsection{Corrosion behavior of coatings onto carbon steel}

Figure $8 \mathbf{a}$ shows the open circuit potential of as-sprayed C1 (porosity $\sim 11$ vol.\%) and C2 (porosity $\sim 6$ vol.\%) coatings onto carbon steel, bulk titanium and bulk carbon steel for 3600 seconds. Open circuit potential of bulk titanium was $-220 \mathrm{mV}$ and carbon steel reached a steady open circuit potential of $-750 \mathrm{mV}$ after 1200 seconds of immersion. As-sprayed C1 coating onto carbon steel reached a steady 
state open circuit potential of $-700 \mathrm{mV}$ after 200 seconds of immersion and remained at that level during the full length of the experiment. As-sprayed C2 coating onto carbon steel showed a decreasing trend in open circuit potential measurements, which started at $-320 \mathrm{mV}$ upon immersion and gradually dropped to $-500 \mathrm{mV}$ after 3600 seconds.

Potentiodynamic polarization scans of $\mathrm{C} 1$ and $\mathrm{C} 2$ coatings onto carbon steel, bulk titanium and carbon steel are shown in Figure 8b. C1 coating showed an Icorr value of $3.5 \times 10^{-3} \mathrm{~mA} / \mathrm{cm}^{2}$ and Ecorr value of $-836 \mathrm{mV}$; and $\mathrm{C} 2$ coating showed an Icorr value of $2 \times 10^{-3} \mathrm{~mA} / \mathrm{cm}^{2}$ and Ecorr value of $-603 \mathrm{mV}$ (Table 3). C1 coating onto carbon steel showed "passive like" corrosion current density of $1.1 \mathrm{~mA} / \mathrm{cm}^{2}$ and C2 coating onto carbon steel showed a value of $0.7 \mathrm{~mA} / \mathrm{cm}^{2}$; these are around two orders of magnitude greater than bulk titanium passive current density of 0.005 $\mathrm{mA} / \mathrm{cm}^{2}$. A piece of carbon steel substrate was also tested under similar conditions for reference. Carbon steel had an Icorr value of $3 \times 10^{-3} \mathrm{~mA} / \mathrm{cm}^{2}$ and Ecorr value of $-750 \mathrm{mV}$. The current density of carbon steel increased rapidly with overpotential and reached a limiting value of $1000 \mathrm{~mA} / \mathrm{cm}^{2}$ at $1050 \mathrm{mV}$.

Figures $9(\mathbf{a}, \mathbf{b})$ show the top surface of $\mathrm{C} 1$ coating after potentiodynamic polarization at low and high magnifications. The optical microscope image of Figure 9a shows evidence of localized corrosion on the sample surface, where the electrolyte percolated through the coating and attacked the carbon steel substrate. Figure 9b shows a higher magnification SEM image of one of the localized corrosion regions. Energy dispersive X-ray analysis in the SEM of the boxed region showed presence of iron, oxygen, sodium and chlorine on the titanium coating surface. 
Figures $10(\mathbf{a}, \mathbf{b})$ show the salt spray (fog) test results of $\mathrm{C} 1$ and $\mathrm{C} 2$ coatings onto carbon steel after 24 hours of exposure. C1 coating showed severely attacked pits on the surface, where distinctive yellow rust from the corrosion of carbon steel substrate was present. The surface of C2 coating showed a large number of small corrosion spots after the test. The coating C2 shows uniformly distributed corrosion product over the entire surface as opposed to a few large corrosion pits in the C1 coating.

\section{Discussion}

\subsection{Microstructure and porosity of titanium}

Although it is possible to produce a pore free microstructure using cold spray from ductile face centered cubic copper [22], it is more difficult to produce a pore free deposit from titanium. Titanium may be more difficult to densify in cold spraying due to its hexagonal closed pack (hcp) crystal structure and its lower density $[16,23]$. A less deformed top porous layer is clearly observed in the deposits sprayed at $600{ }^{\circ} \mathrm{C}$, whereas, this porous layer is less evident in the deposits sprayed at $800^{\circ} \mathrm{C}$. It can be argued that there are two effects taking place at the higher process gas temperature. First, the particles reach a higher in-flight velocity due to a higher Mach number inside the gun and secondly, the particles reach a higher temperature in the gas stream. According to the energy balance theory the initial kinetic energy of a particle before impact is the sum of the energy dissipated as plastic deformation plus recoverable strain energy [24]. A higher particle velocity results in a greater kinetic 
energy which enhances plastic deformation. Also heating of the particles changes the initial state of impacting bodies due to thermal softening that results in a decrease of flow stress. Also, the porosity of titanium deposits decreases with increasing the distance from the coating top surface because the particles at the bottom of the coating experience more of a peening effect than the particles deposited at the top surface [13].

The shear lips of the titanium particles observed at the top surface of the coating sprayed at $800{ }^{\circ} \mathrm{C}$ process gas temperature (Figure 4d) can be attributed to the highly localized temperature increase at the impacting interface due to a relatively low thermal conductivity and a low diffusivity of titanium [15]. During this high strain rate plastic deformation of titanium, much of the work done is converted to heat [25]. On the other hand, partial bonding and ruptured bonds in the deposits sprayed at $600{ }^{\circ} \mathrm{C}$ (Figure 4c) can be attributed to elastic relief on unloading during the impact phenomena [26]. These differences in deformation of the particles and thermal softening resulted in an open porosity of $\sim 6 \mathrm{vol} . \%$ in the deposits sprayed at $800{ }^{\circ} \mathrm{C}$ compared to $\sim 11 \mathrm{vol}$. \% of the deposits sprayed at $600{ }^{\circ} \mathrm{C}$ as determined from MIP.

It was evidenced from the micrographs, Figures $4(\mathbf{g}, \mathbf{h})$, that heat treatment of free standing titanium deposits above the $\beta$ transus temperature resulted in grain growth and reduction in porosity. Titanium has an adherent oxide $\left(\mathrm{TiO}_{2}\right)$ layer which has to be disrupted to form metallurgical bonds [20, 27]. Moreover, the oxide layer on the metal surface acts as a diffusion barrier for many metals but $\mathrm{TiO}_{2}$ does not hinder the formation of metallurgical bonds during heat treatment because both a 
and $\beta$ phases of titanium are known to dissolve oxygen interstitially [28]. Therefore, during vacuum heat treatment new grains were formed and grain growth took place, which eliminated the sprayed particle boundaries [29]. Consequently, the interparticle pores in the as-sprayed deposits were pinned down at the new grain boundaries. In summary, heat treatment resulted in a reduction of open porosity in FS1 from $\sim 11$ vol. $\%$ to $~ 5$ vol. $\%$ and in FS2 from $\sim 6$ vol. $\%$ to $~ 2$ vol. \%.

Mercury intrusion porosimetry (MIP) measured the interconnected porosity of the assprayed and the heat treated free standing deposits down to a few $\mathrm{nm}$ of pore sizes, estimated from equation 1 . This is well below the resolution of an optical microscope. If an optical microscope with a typical resolution of $1 \mu \mathrm{m}$ were to be used to measure the porosity of heat treated FS2, the deposit would appear to have a porosity of only $\sim 0.2 \%$ because the sub-micron pores would not be resolved (Table 2 ). However, the majority of the pores in the heat treated FS2 were of sub-micron sizes which account for a porosity of 1.6 vol. \%. Moreover, MIP has a unique advantage in measuring the volume percentage of porosity in cold sprayed coatings compared with thermally sprayed metals because the formation of oxide can be neglected. Therefore MIP cumulative intrusion values can readily be converted to volume percentage of porosity using the known density of metallic Ti. In thermally sprayed coatings, the volume percentage and density of any oxide inclusions also need to be known before the cumulative intrusion values in $\mathrm{mL}$ of mercury per gram of sample can be converted to volume percentage of porosity. 


\subsection{Corrosion behavior of free standing deposits}

In thermally sprayed coatings, open circuit potential (OCP) measurements and potentiodynamic polarization scans have been widely used to evaluate the corrosion behavior [30-33]. In the present potentiodynamic experiments, heat treated FS1, as-sprayed FS2, and heat treated FS2 deposits show a passive current density similar to the bulk titanium, which means that the change in porosity level from $\sim 6$ vol. $\%$ to $\sim 2$ vol. $\%$ does not have a significant effect on the passive current density. However, the as-sprayed free standing deposit FS1 with a porosity of $\sim 11$ vol. \% shows an increased passive current density (by 1-2 orders of magnitude). This could be due to an increase in "true surface area" taking part in the corrosion reactions. In support of this, a similar increase in passive current density with increasing porosity in sintered and warm sprayed titanium has also been reported in literature $[7,34]$. Moreover, in contrast to APS, arc, or flame sprayed titanium deposits, cold sprayed titanium deposits are apparently free from oxides and nitrides, and hence the increase in passive current density is unlikely to arise from the presence of such phases. In this study, the open circuit potentials of all the deposits show more negative values compared to the bulk titanium, which means that the deposits had active surfaces and higher thermodynamic tendency to corrosion [3]. Also, the open circuit potentials of the deposits did not show any decreasing trend with time because of the stability of the protective oxide film [35]. Also it would appear that open circuit potentials and Ecorr values are more sensitive to small amounts of porosity than are passive current densities. In Figure 7a, the heat treated deposit FS2 is seen to be cathodic with respect to bulk titanium whereas Figure 7b shows an identical passive current density. 
Corrosion current density (Icorr) is directly proportional to the corrosion rate of the material and in this study, potentiodynamic polarization scans showed that Icorr of free standing deposit FS2 ( 6 vol. \% porosity) is an order of magnitude smaller than FS1 ( 11 vol. \%). In addition, heat treatment of both FS1 and FS2 deposits reduced the Icorr by 1-2 orders of magnitude. It was reported in several studies that corrosion performance of sprayed deposits improved following heat treatment [31, 36]. Heat treatment of porous titanium deposits eliminates the smaller pores to produce a more homogenous structure and the surface oxide of the particles is removed during heat treatment in a vacuum [36]. Moreover, cold sprayed deposits contain highly deformed particles because of the high velocity impacts and high strain rate plastic deformation of the particles [37]. These highly deformed particles could act as preferential sites for corrosion [9]. Heat treatment of the as-sprayed deposits also eliminates these high stressed regions and thus reduces the preferential corrosion attack.

\subsection{Corrosion behavior of coatings onto carbon steel}

Open circuit potential is widely used as a method to assess the effect of interconnected porosity in sprayed coatings [2, 10, 33]. A barrier coating layer will show an open circuit potential very close to that of the coating material whereas a porous coating, that allows the corrosive liquid to attack the substrate, will show an open circuit potential closer to the substrate material. In this study, both the coated samples $\mathrm{C} 1$ and $\mathrm{C} 2$ had open circuit potential values in between bulk titanium and carbon steel substrate, which indicates salt solution percolation through the coatings. As-sprayed C2 coating (porosity $\sim 6$ vol. \%) had an open circuit potential closer to bulk titanium for first few hundred seconds and then the open circuit potential decreased; presumably when the solution started percolating through the coating 
and attacking the substrate. However, with $\mathrm{C} 1$ coating (porosity $\sim 11$ vol. \%) the open circuit potential decreased to the carbon steel value within few tens seconds of immersion. Furthermore, $\mathrm{C} 1$ coating had a coarser pore size distribution $(0.3-8 \mu \mathrm{m})$ than that of $\mathrm{C} 2(0.18-1.6)$ which possibly allowed the solution to percolate through the coating readily. It should also be mentioned that although $\mathrm{C} 1$ coating was thicker than C2 coating, by around $\sim 300 \mu \mathrm{m}$, this increased thickness did not provide any increased corrosion resistance! Clearly, therefore less interconnected porosity in coatings plays the major role in corrosion resistance over increased thickness.

Salt spray test results also confirmed the lack of barrier like properties of coatings C1 and C2 (Figures 10 a, b). It is clear that C1 coating, which had a higher porosity and larger pores, exhibited only a few but large corrosion spots compared to C2 coating. One explanation for this is that once the corrosion of the substrate started due to galvanic effect, it had a higher driving force to continue corroding at the attacked sites instead of forming new pits. In aggressive environments like salt spray test, micro galvanic cells are formed across the titanium- carbon steel interface which ultimately results in delamination of the coating.

As expected, potentiodynamic polarization scans of the coatings onto carbon steel resulted in a higher anodic corrosion current compared to the bulk titanium sheet. These differences in current density were also due to the percolation of the solution through the coating. The lower amount of porosity in C2 coating compared to C1 resulted in a decrease in anodic current. A study by Wang et al. [11] also showed that cold sprayed titanium coating with a lower porosity resulted in a lower anodic corrosion current in salt solution. However, the densest coating (1.6\%) in that study, 
which was measured using image analysis techniques, showed increased anodic corrosion current (by two orders of magnitude) compared to bulk titanium. Moreover, this behavior of reduction of anodic current with decreasing porosity was also observed in HVOF coatings and plasma sprayed titanium coatings because of a reduction in active corrosion sites on the substrate $[36,38]$.

Future work to improve the corrosion performance of cold sprayed titanium coating should thus focus on enhancing the particle deformation during cold spraying to ensure the elimination of even sub-micron porosity which cannot be observed in the optical microscope but is measurable using MIP. Surface treatment of the top layer of titanium coatings could also be investigated in order to achieve barrier coating properties.

\section{Conclusions}

Titanium was deposited by cold gas dynamic spraying using two different process parameters designed to reduce porosity. The porosity of the deposits was characterized by mercury intrusion porosimetry. The deposits were heat treated to reduce porosity and the effect of porosity on the corrosion performance of free standing titanium deposits was studied in 3.5 wt. \% $\mathrm{NaCl}$ solution. Corrosion performance of titanium coatings onto carbon steel was also investigated in the same solution using electrochemical methods and salt spray tests. The following conclusions were drawn from the above study: 
- Cold spraying using $\mathrm{N}_{2}$ as a process gas heated to $800{ }^{\circ} \mathrm{C}$ can deposit titanium with less interconnected porosity than $\mathrm{N}_{2}$ gas at $600{ }^{\circ} \mathrm{C}$ due to a higher degree of particle deformation on impact. Mercury intrusion porosimetry can be successfully used to measure total interconnected porosity, including sub-micron pores, in free standing deposits.

- A pore free microstructure of titanium deposit could not be achieved from cold spraying alone. However, vacuum heat treatment of free standing titanium deposits significantly reduced the interconnected porosity. Pores above $1 \mu \mathrm{m}$ were reduced to $0.2 \mathrm{vol}$. $\%$ and the total interconnected porosity to $1.8 \mathrm{vol}$. $\%$ following heat treatment of deposits produced at a process gas temperature of $800^{\circ} \mathrm{C}$.

- Open circuit potentials (OCP) and rest potentials (Ecorr) are more sensitive to small amounts of porosity than are passive current densities (Ipp). However, OCP values of free standing titanium deposits were, in all cases, lower than that of bulk titanium due to porosity even after vacuum heat treatment.

- Electrochemical corrosion studies of the titanium coatings on carbon steel substrate showed significant substrate influence at the levels of porosity arising from deposition at both $600^{\circ} \mathrm{C}$ and $800{ }^{\circ} \mathrm{C}$. Open circuit potentials and passive current densities of the coatings were significantly different from that of bulk titanium due to the interconnected porosity. Salt spray tests also confirmed the presence of interconnected porosity in these coatings.

\section{Acknowledgements}

T. Hussain acknowledges financial support from the University of Nottingham through the award of an Overseas Research Studentship (ORS) and industrial 
sponsorship from TWI Ltd., UK for his research. The authors thank Dr. C M Lee from TWI, Cambridge, UK for useful discussion on the corrosion measurement. 


\section{References}

1. J.F. Sun, Y. Han, and K. Cui, Innovative Fabrication of Porous Titanium Coating on Titanium by Cold Spraying and Vacuum Sintering, Mater. Lett., 2008, 62(21-22), p. 3623-3625

2. H.R. Wang, W.Y. Li, L. Ma, J. Wang, and Q. Wang, Corrosion Behavior of Cold Sprayed Titanium Protective Coating on $1 \mathrm{cr} 13$ Substrate in Seawater, Surf. Coat. Technol., 2007, 201(9-11), p. 5203-5206

3. W.M. Zhao, C. Liu, L.X. Dong, and Y. Wang, Effects of Arc Spray Process Parameters on Corrosion Resistance of Ti Coatings, J. Therm. Spray Technol., 2009, 18(4), p. 702-707

4. K. Ishikawa, T. Suzuki, Y. Kitamura, and S. Tobe, Corrosion Resistance of Thermal Sprayed Titanium Coatings in Chloride Solution, J. Therm. Spray Technol., 1999, 8(2), p. 273-278

5. T. Kinos, S. Chen, P. Siitonen, and P. Kettunen, Densification of PlasmaSprayed Titanium and Tantalum Coatings, J. Therm. Spray Technol., 1996, 5(4), p. 439-444

6. T. Kinos, S.L. Chen, P. Siitonen, and P. Kettunen, Corrosion Properties of Shrouded Plasma Sprayed Titanium Coatings, Thermal Spraying: Current Status and Future Trends, A. Ohmori, Ed., May 22-26, 1995 (Kobe, Japan), High Temperature Society of Japan, 1995, p. 573-576

7. J. Kawakita, H. Katanoda, M. Watanabe, K. Yokoyama, and S. Kuroda, Warm Spraying: An Improved Spray Process to Deposit Novel Coatings, Surf. Coat. Technol., 2008, 202(18), p. 4369-4373

8. J. Kawakita, S. Kuroda, T. Fukushima, H. Katanoda, K. Matsuo, and H. Fukanuma, Dense Titanium Coatings by Modified Hvof Spraying, Surf. Coat. Technol., 2006, 201(3-4), p. 1250-1255

9. K. Balani, T. Laha, A. Agarwal, J. Karthikeyan, and N. Munroe, Effect of Carrier Gases on Microstructural and Electrochemical Behavior of ColdSprayed 1100 Aluminum Coating, Surf. Coat. Technol., 2005, 195(2-3), p. 272-279

10. H. Koivuluoto, J. Näkki, and P. Vuoristo, Corrosion Properties of Cold-Sprayed Tantalum Coatings, J. Therm. Spray Technol., 2009, 18(1), p. 75-82

11. H.R. Wang, B.R. Hou, J. Wang, Q. Wang, and W.Y. Li, Effect of Process Conditions on Microstructure and Corrosion Resistance of Cold-Sprayed $\mathrm{Ti}$ Coatings, J. Therm. Spray Technol., 2008, 17(5), p. 736-741

12. H. Koivuluoto, M. Honkanen, and P. Vuoristo, Cold-Sprayed Copper and Tantalum Coatings -- Detailed FESEM and TEM Analysis, Surf. Coat. Technol., 2010, 204(15), p. 2353-2361

13. C.J. Li, and W.Y. Li, Microstructure Evolution of Cold-Sprayed Coating During Deposition and through Post-Spraying Heat Treatment, Transactions of Nonferrous Metals Society of China (English Edition), 2004, 14(SUPPL. 2), p. 49-54

14. C.J. Li, and W.Y. Li, Deposition Characteristics of Titanium Coating in Cold Spraying, Surf. Coat. Technol., 2003, 167(2-3), p. 278-283

15. W.Y. Li, C. Zhang, H.T. Wang, X.P. Guo, H.L. Liao, C.J. Li, and C. Coddet, Significant Influences of Metal Reactivity and Oxide Films at Particle Surfaces on Coating Microstructure in Cold Spraying, Appl. Surf. Sci., 2007, 253(7), p. 3557-3562 
16. T. Marrocco, D.G. Mccartney, P.H. Shipway, and A.J. Sturgeon, Production of Titanium Deposits by Cold-Gas Dynamic Spray: Numerical Modeling and Experimental Characterization, J. Therm. Spray Technol., 2006, 15(2), p. 263-272

17. S.H. Zahiri, C.L. Antonio, and M. Jahedi, Elimination of Porosity in Directly Fabricated Titanium Via Cold Gas Dynamic Spraying, J. Mater. Process. Technol., 2009, 209(2), p. 922-929

18. S.H. Zahiri, W. Yang, and M. Jahedi, Characterization of Cold Spray Titanium Supersonic Jet, J. Therm. Spray Technol., 2009, 18(1), p. 110-117

19. W. Wong, A. Rezaeiann, E. Irissou, J.G. Legoux, and S. Yue, Cold Spray Characteristics of Commercially Pure $\mathrm{Ti}$ and Ti-6al-4v, Advanced Materials Research, 2010, 89-91, p. 639-644

20. T.S. Price, P.H. Shipway, D.G. Mccartney, E. Calla, and D. Zhang, A Method for Characterizing the Degree of Inter-Particle Bond Formation in Cold Sprayed Coatings, J. Therm. Spray Technol., 2007, 16(4), p. 566-570

21. G. Bae, S. Kumar, S. Yoon, K. Kang, H. Na, H.-J. Kim, and C. Lee, Bonding Features and Associated Mechanisms in Kinetic Sprayed Titanium Coatings, Acta Mater., 2009, 57(19), p. 5654-5666

22. H. Koivuluoto, M. Honkanen, and P. Vuoristo, Cold-Sprayed Copper and Tantalum Coatings -- Detailed Fesem and Tem Analysis, Surf. Coat. Technol., 204(15), p. 2353-2361

23. J. Vlcek, L. Gimeno, H. Huber, and E. Lugscheider, A Systematic Approach to Material Eligibility for the Cold-Spray Process, J. Therm. Spray Technol., 2005, 14(1), p. 125-133

24. G. Bae, Y. Xiong, S. Kumar, K. Kang, and C. Lee, General Aspects of Interface Bonding in Kinetic Sprayed Coatings, Acta Mater., 2008, 56(17), p. 48584868

25. R. Kapoor, and S. Nemat-Nasser, Determination of Temperature Rise During High Strain Rate Deformation, Mechanics of Materials, 1998, 27(1), p. 1-12

26. J.W. Wu, H.Y. Fang, S. Yoon, H. Kim, and C. Lee, The Rebound Phenomenon in Kinetic Spraying Deposition, Scr. Mater., 2006, 54(4), p. 665-669

27. T. Hussain, D.G. Mccartney, P.H. Shipway, and D. Zhang, Bonding Mechanisms in Cold Spraying: The Contributions of Metallurgical and Mechanical Components, J. Therm. Spray Technol., 2009, 18(3), p. 364-379

28. P. Waldner, Modelling of Oxygen Solubility in Titanium, Scr. Mater., 1999, 40(8), p. 969-974

29. H.R.S. Jazi, T.W. Coyle, and J. Mostaghimi, Understanding Grain Growth and Pore Elimination in Vacuum-Plasma-Sprayed Titanium Alloy, Metall. Mater. Trans. A-Phys. Metall. Mater. Sci., 2007, 38A(3), p. 476-484

30. D. Chidambaram, C.R. Clayton, and M.R. Dorfman, Evaluation of the Electrochemical Behavior of Hvof-Sprayed Alloy Coatings--Ii, Surf. Coat. Technol., 2005, 192(2-3), p. 278-283

31. G. Bolelli, L. Lusvarghi, and M. Barletta, Heat Treatment Effects on the Corrosion Resistance of Some Hvof-Sprayed Metal Alloy Coatings, Surf. Coat. Technol., 2008, 202(19), p. 4839-4847

32. P. Siitonen, S.L. Chen, K. Niemi, and P. Vuoristo, Electrochemical Method for Evaluating the Corrosion Resistance and Porosity of Thermal Sprayed Coatings, Thermal Spray: International Advances in Coatings Technology, C.C. Berndt, Ed., May 25 - June 5, 1992 (Orlando, FL), ASM International, 1992 , p. $853-858$ 
33. R. Hofman, M.P.W. Vreijling, G.M. Ferrari, and J.H.W. De Wit, Electrochemical Methods for Characterisation of Thermal Spray Corrosion Resistant Stainless Steel Coatings, Electrochemical Methods in Corrosion Research Vi, Pts 1 and 2, P.L. Bonora and F. Deflorian, Eds., Transtec Publications Ltd, 1998, p. 641653

34. N. Ahmed, M.S. Bakare, D.G. Mccartney, and K.T. Voisey, The Effects of Microstructural Features on the Performance Gap in Corrosion Resistance between Bulk and Hvof Sprayed Inconel 625, Surf. Coat. Technol., 2010, 204(14), p. 2294-2301

35. J.D. Ayers, R.J. Schaefer, F.D. Bogar, and E. Mccafferty, Corrosion Behavior of Laser Consolidated Titanium Coated Steel in Sea-Water, Corrosion, 1981, $37(1)$, p. $55-57$

36. J. Kawakita, S. Kuroda, T. Fukushima, and T. Kodama, Development of Dense Corrosion Resistant Coatings by an Improved Hvof Spraying Process, Science and Technology of Advanced Materials, 2003, 4(4), p. 281-289

37. R.C. Mccune, W.T. Donlon, O.O. Popoola, and E.L. Cartwright, Characterization of Copper Layers Produced by Cold Gas-Dynamic Spraying, J. Therm. Spray Technol., 2000, 9(1), p. 73-82

38. T. Valente, and F.P. Galliano, Corrosion Resistance Properties of Reactive Plasma-Sprayed Titanium Composite Coatings, Surf. Coat. Technol., 2000, $127(1)$, p. $86-92$ 
Figure 1 (a) SEM image of gas atomized titanium feedstock powder showing its near-spherical morphology. (b) Cumulative size distribution of titanium powder measured by laser diffractrometry

Figure 2 Lower magnification unetched optical micrographs of titanium coatings onto carbon steel: (a) C1 (b) C2. Higher magnification etched optical micrographs of as-sprayed free standing deposits: (c) FS1 (d) FS2. Higher magnification etched optical micrographs of heat treated free standing deposits: (e) FS1 (f) FS2

Figure 3 SEM images of etched samples showing changes in pore structure of free standing deposits before and after heat treatment (a) As-sprayed FS1 (b) As-sprayed FS2 (c) Heat treated FS1 (d) Heat treated FS2 (Arrows showing the interparticle pores and boxed region showing metallurgical bonding)

Figure 4 SEM images of the top view of free standing deposit before and after heat treatment. Lower magnification images of (a) As-sprayed FS1 (b) As-sprayed FS2. Higher magnification images of (c) As-sprayed FS1 (boxed area showing rupture of bonds) (d) As-sprayed FS2 (Arrows showing viscous flow of material jet). Lower magnification images of heat treated free standing deposit showing changes in microstructure (e) Heat treated FS1 (f) Heat treated FS2. Higher magnification images of heat treated free standing deposits $(\mathrm{g})$ Heat treated FS1 $(\mathrm{h})$ Heat treated FS2

Figure 5 (a) Incremental intrusion of mercury versus pore size of FS1 and FS2 deposits before and after heat treatment (b) Cumulative mercury intrusion of the free standing FS1 and FS2 deposits before and after heat treatment.

Figure 6 (a) Open circuit potential (OCP) of bulk titanium, as-sprayed free standing FS1 deposit and heat treated free standing FS1 deposit in de-aerated $3.5 \mathrm{wt} . \% \mathrm{NaCl}$ 
solution. (b) Potentiodynamic polarization scans of bulk titanium, as-sprayed free standing FS1 deposit and heat treated free standing FS1 deposit in the same solution Figure 7 (a) Open circuit potential of bulk titanium, as-sprayed free standing FS2 deposit and heat treated free standing FS2 deposit in de-aerated $3.5 \mathrm{wt}$. $\% \mathrm{NaCl}$ solution. (b) Potentiodynamic polarization scans of bulk titanium, as-sprayed free standing FS2 deposit and heat treated free standing FS2 deposit in the same solution Figure 8 (a) Open circuit potential of bulk titanium, carbon steel, C1 coating onto carbon steel and C2 coating onto carbon steel in de-aerated 3.5 wt.\% NaCl solution. (b) Potentiodynamic polarization scans of bulk titanium, carbon steel, C1 coating onto carbon steel and C2 coating onto carbon steel in the same solution

Figure 9 (a) Optical microscope image of the top view of $\mathrm{C} 1$ coating onto carbon steel showing localized corrosion following open circuit potential and potentiodynamic polarization scans in $3.5 \mathrm{wt} \% \mathrm{NaCl}$. (b) Higher magnification SEM (SE) image of one of those areas attacked by the corrosive solution

Figure $\mathbf{1 0}$ Low magnification optical macrographs of salt spray (fog) sample surface after 24 hours of exposure. (a) C1 coating onto carbon steel showing larger localized corrosion spots (b) C2 coating onto carbon steel showing more uniformly distributed corrosion spots 
Table 1 Process parameters of cold spraying of titanium $600^{\circ} \mathrm{C}$ and $800^{\circ} \mathrm{C}$ coating

Table 2 Volume fraction of interconnected porosity of free standing FS1 and FS2 deposits before and after heat treatment

Table 3 Open circuit potential (OCP), rest potential (Ecorr), corrosion current density (Icorr) and passive current density (Ipp) of free standing deposits (FS1, FS2) before and after heat treatment, and coatings $(\mathrm{C} 1, \mathrm{C} 2)$ onto carbon steel 


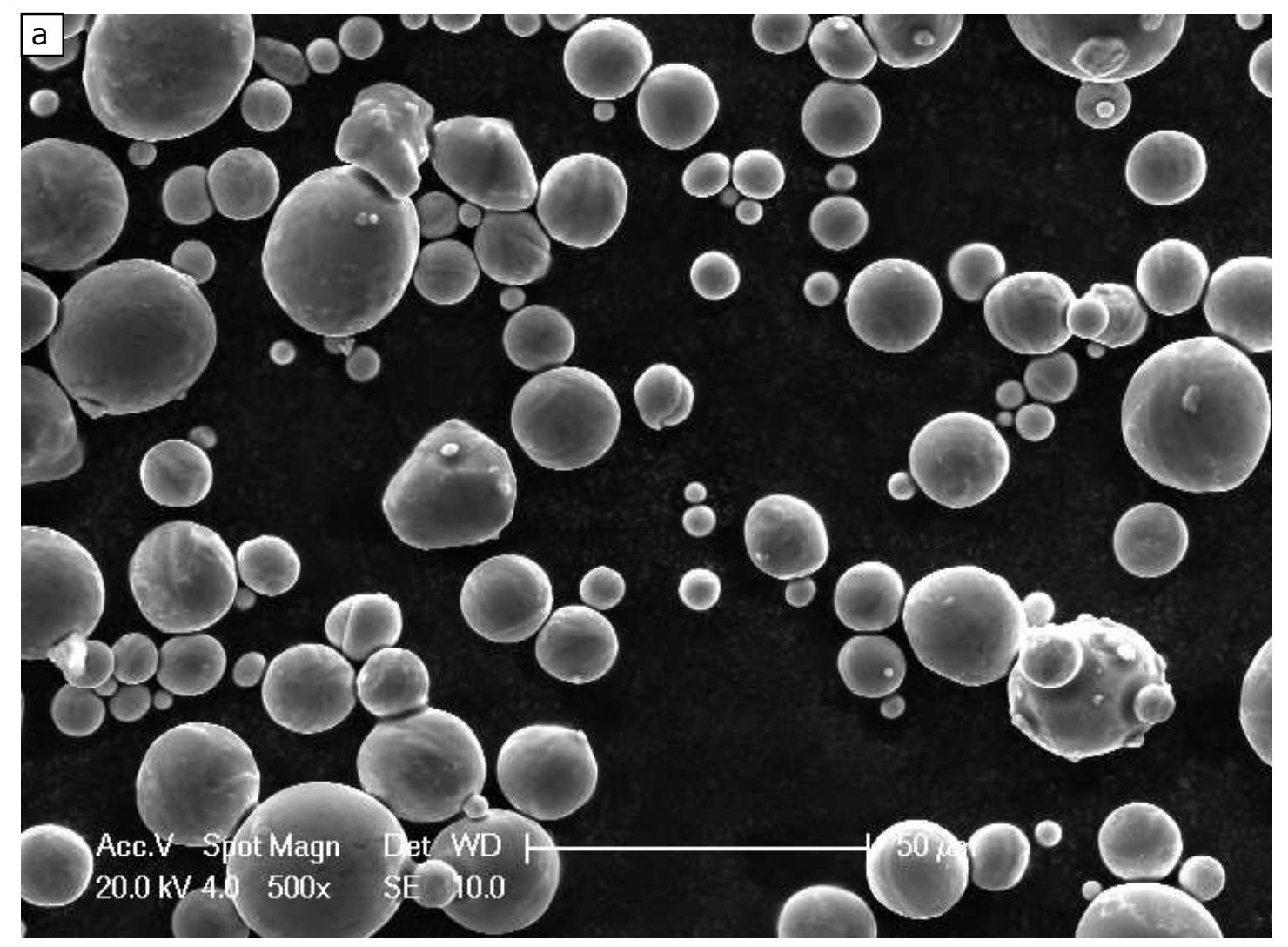

b

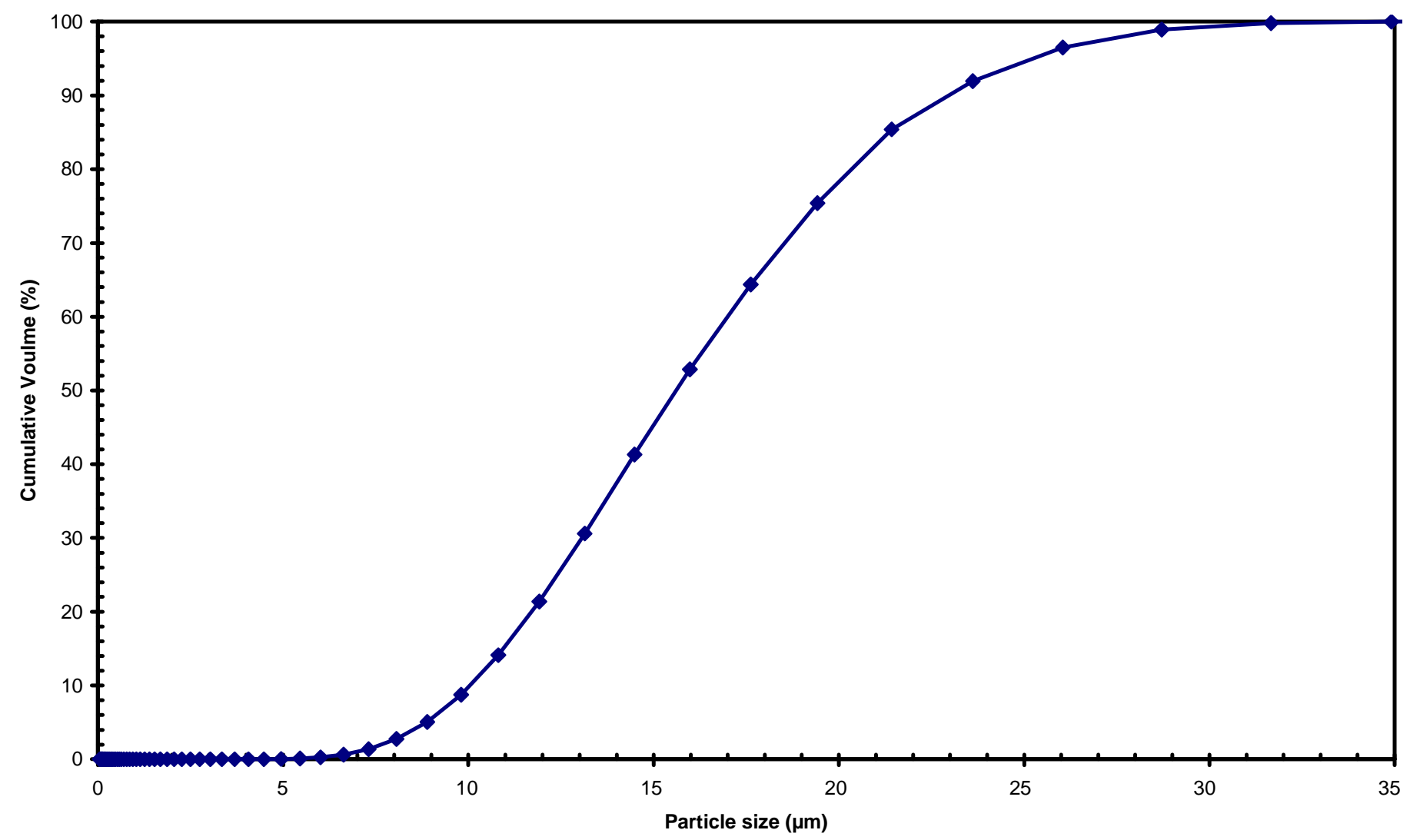

Figure 11 

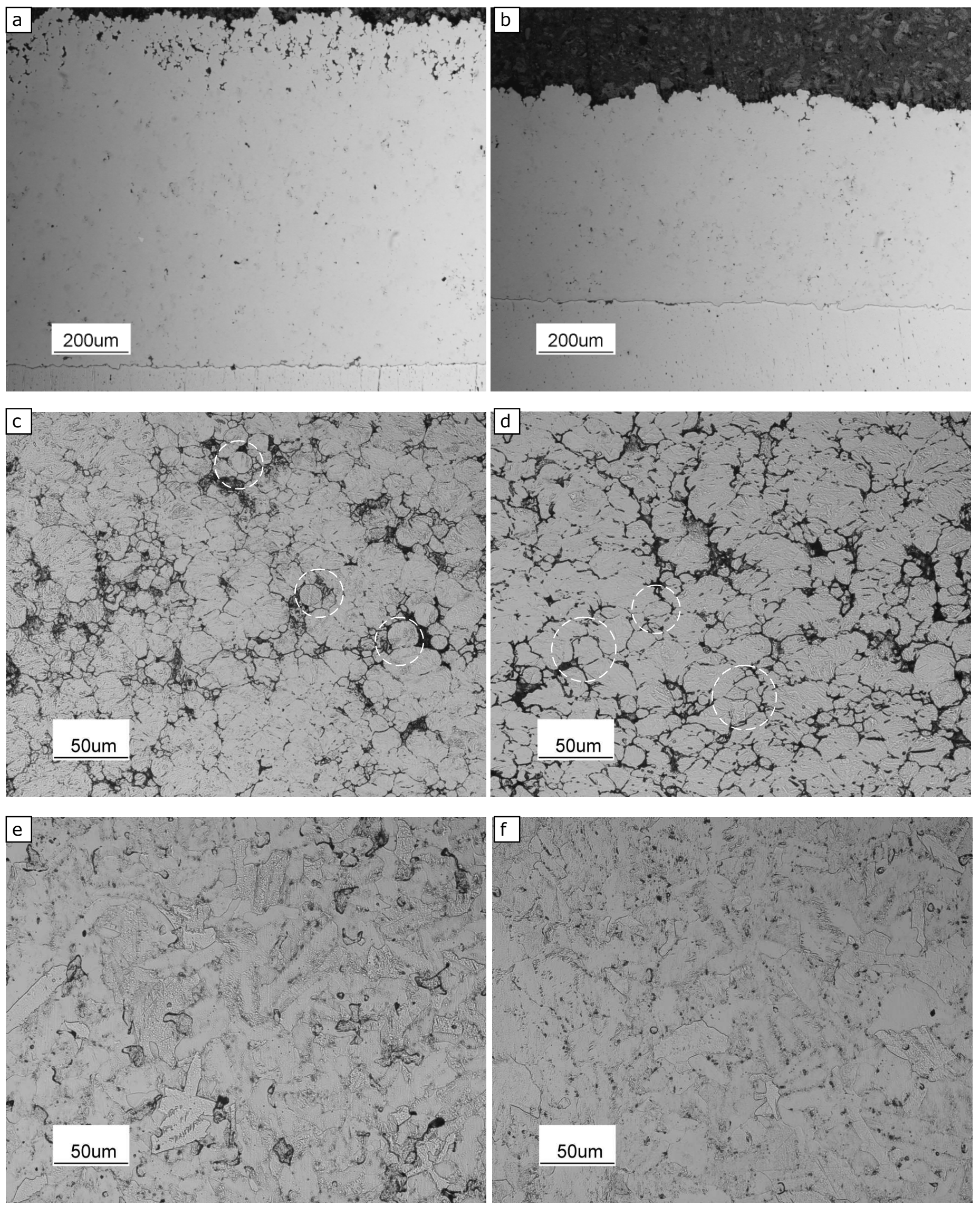

\section{Figure 12}



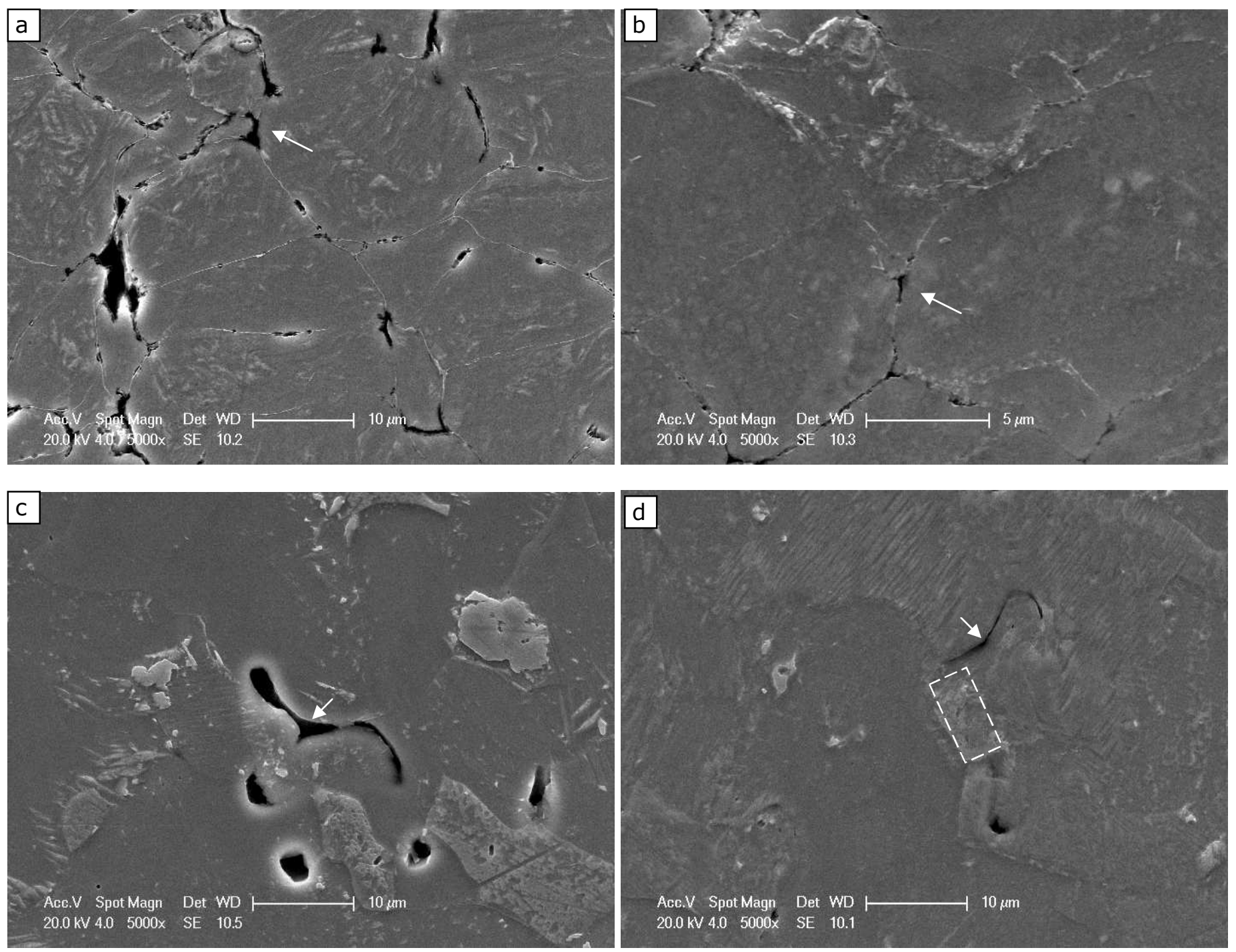

\section{Figure 13}



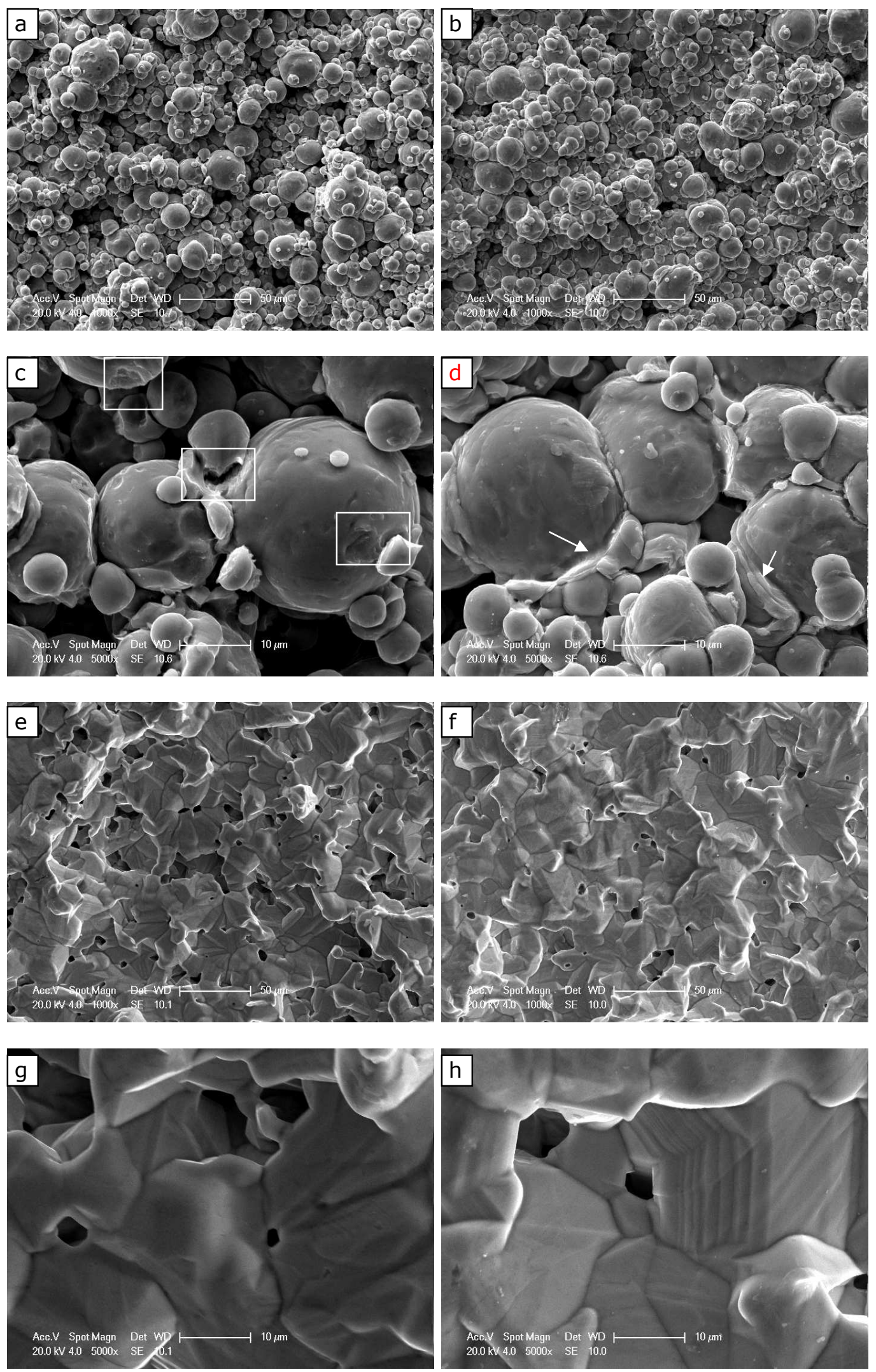

Figure 14 
$a$

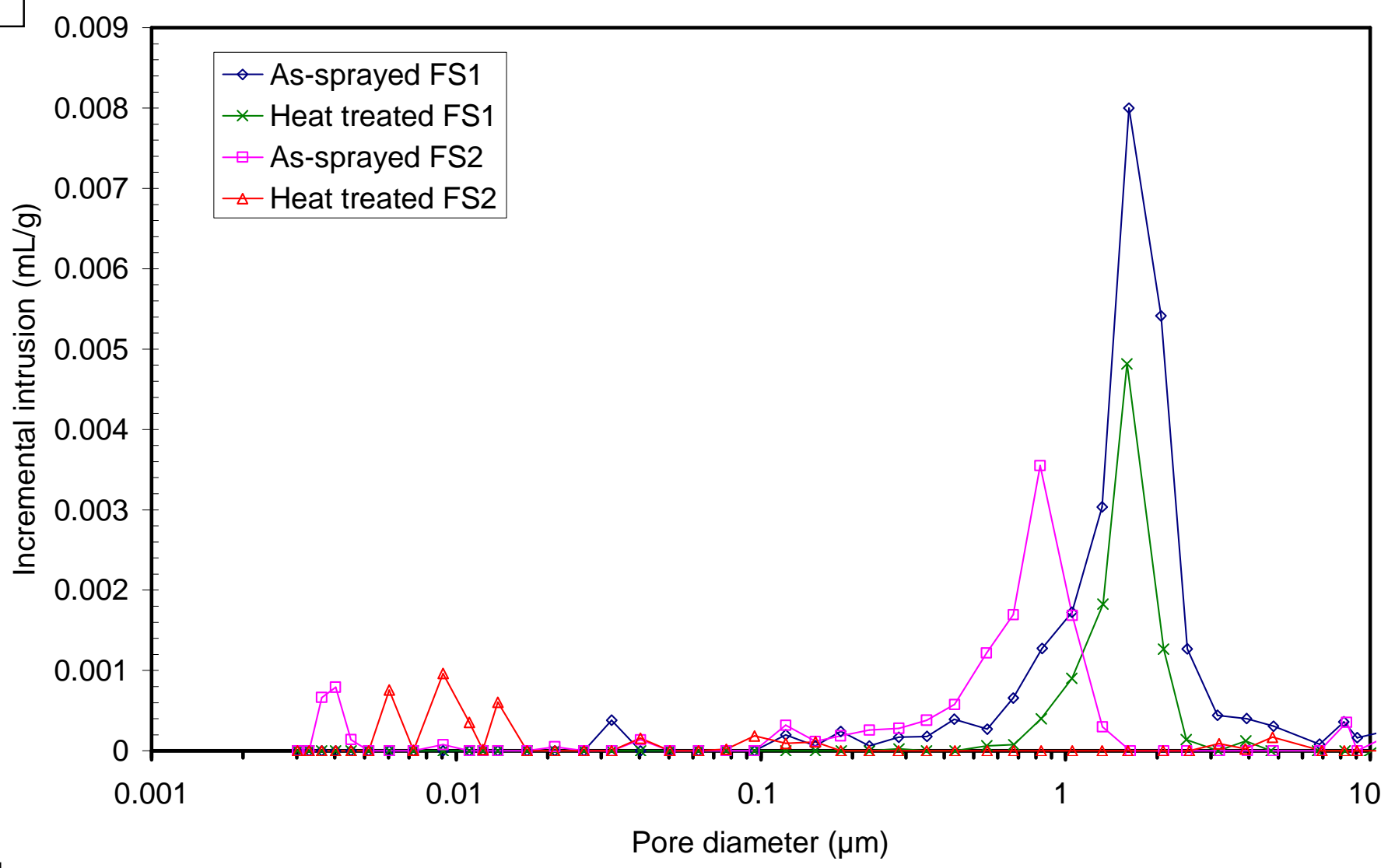

b

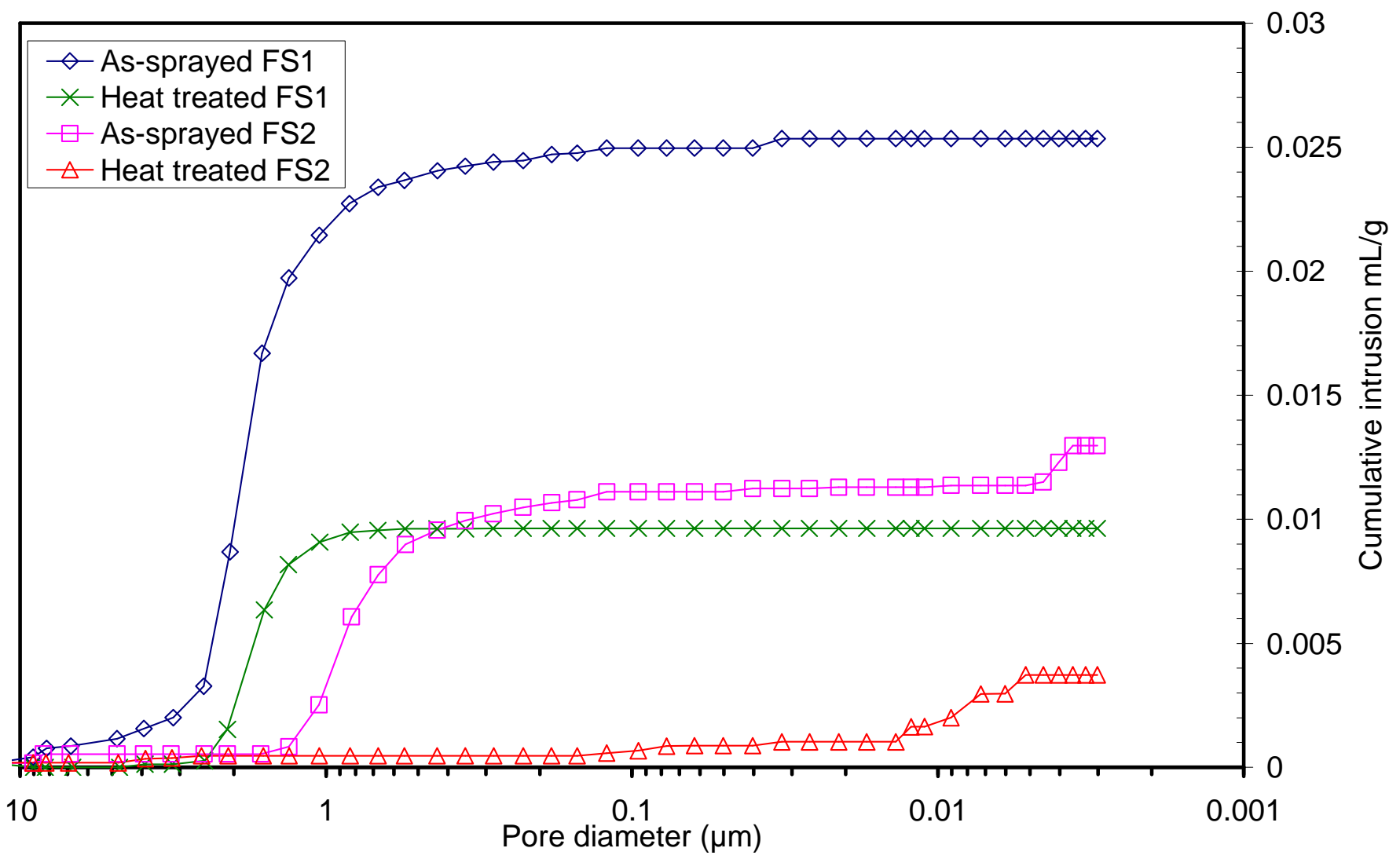

Figure 15 

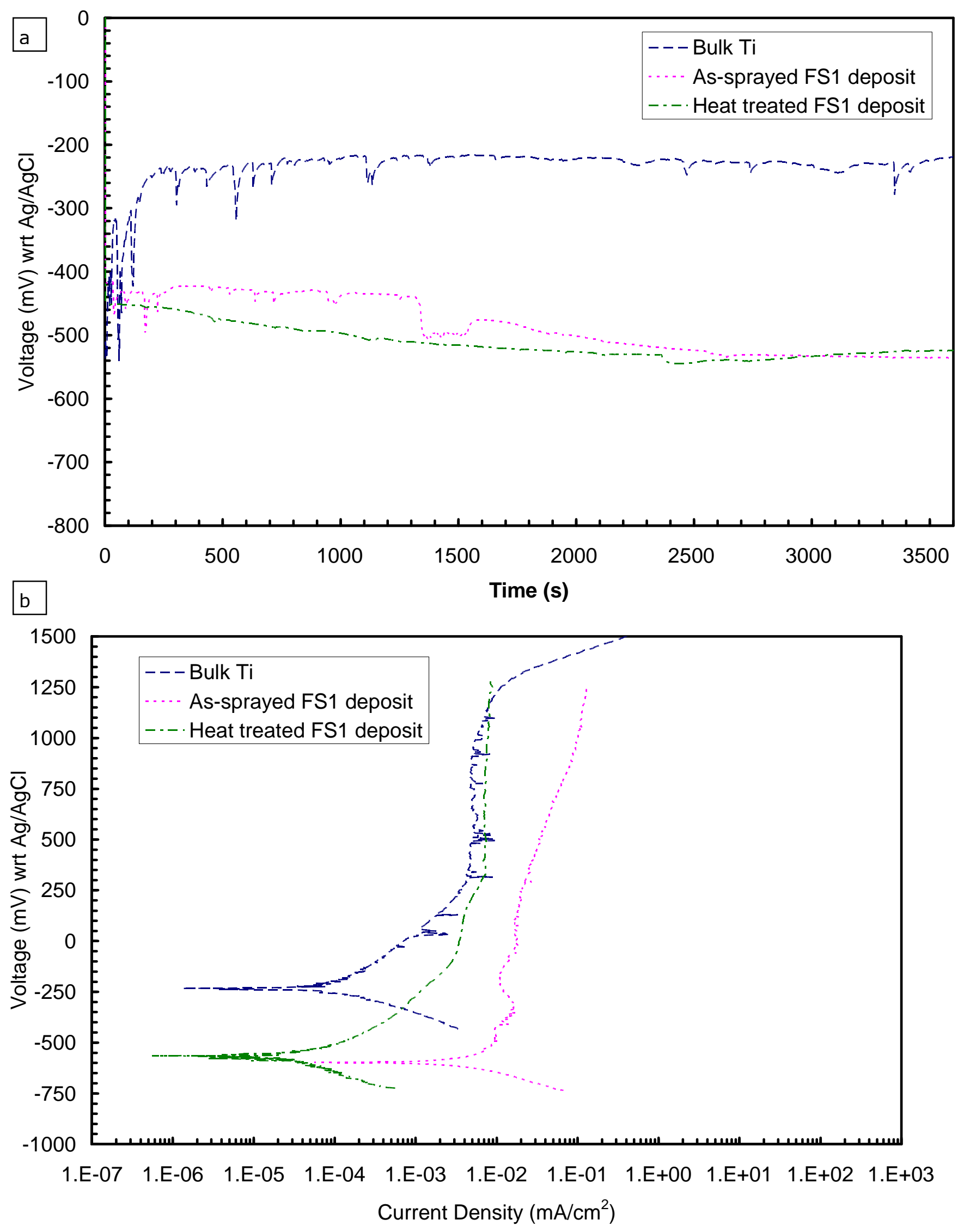

Figure 16 

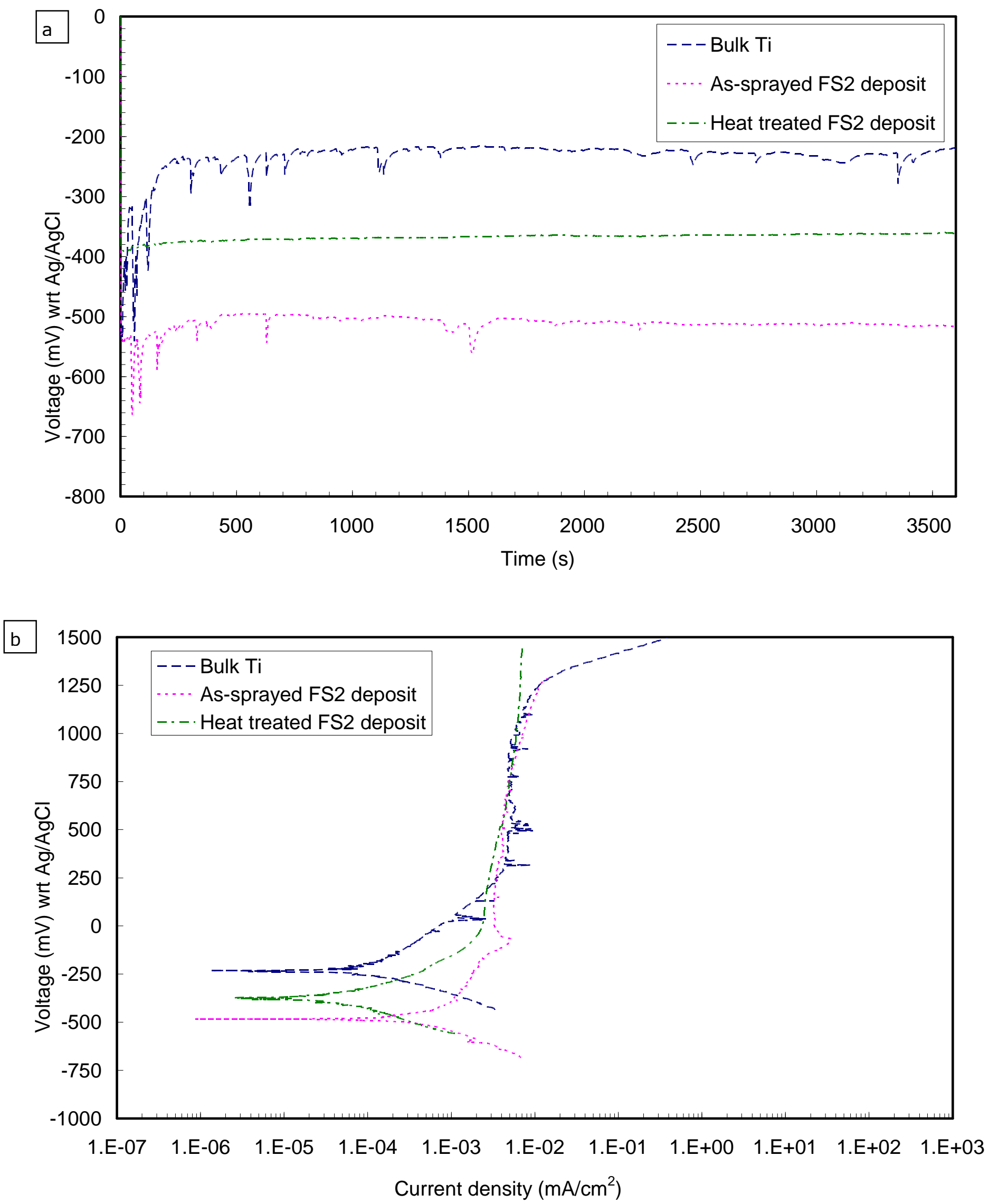

Figure 17 

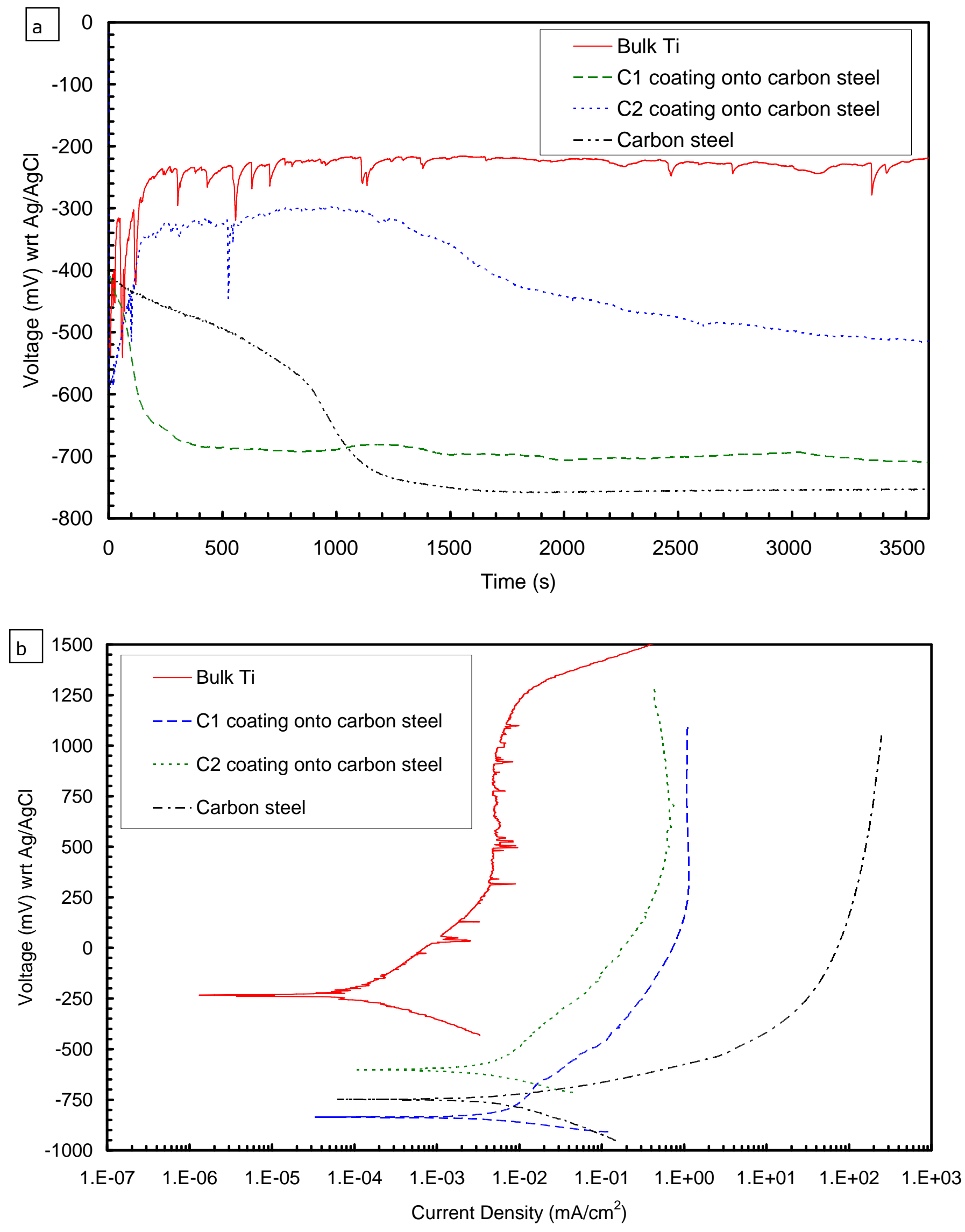

Figure 18 

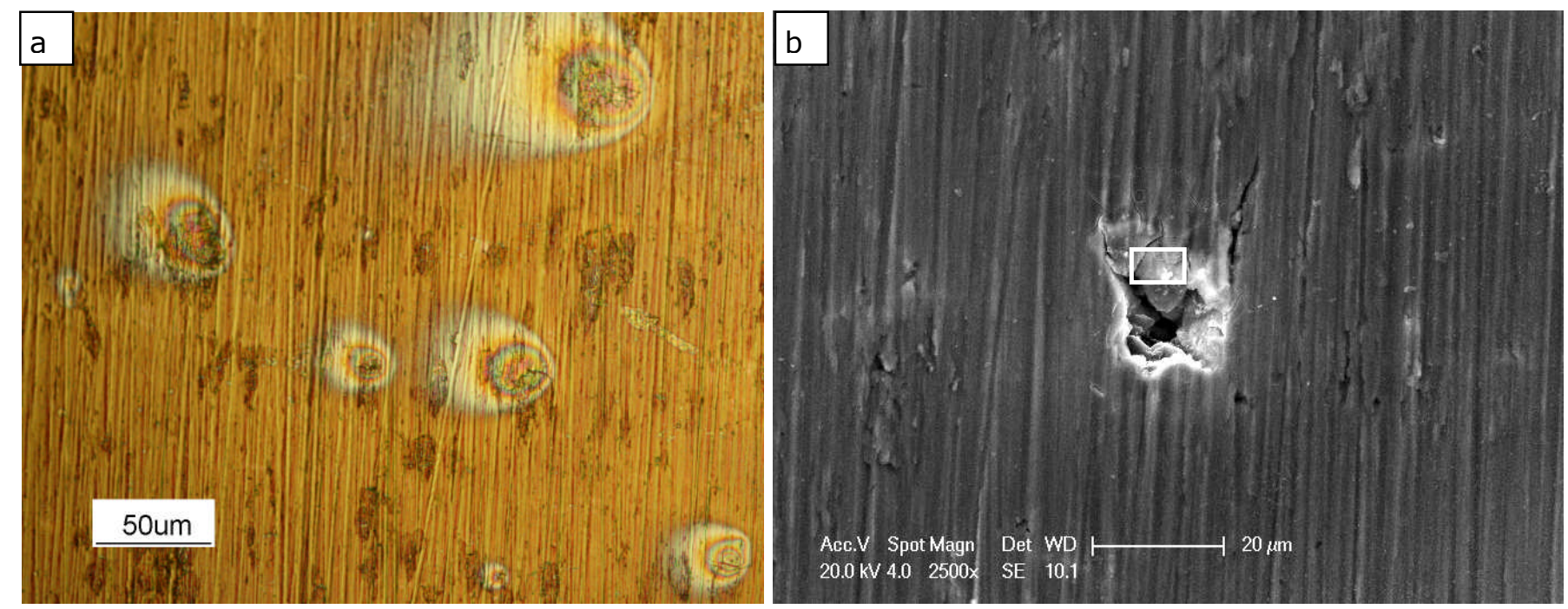

Figure 19
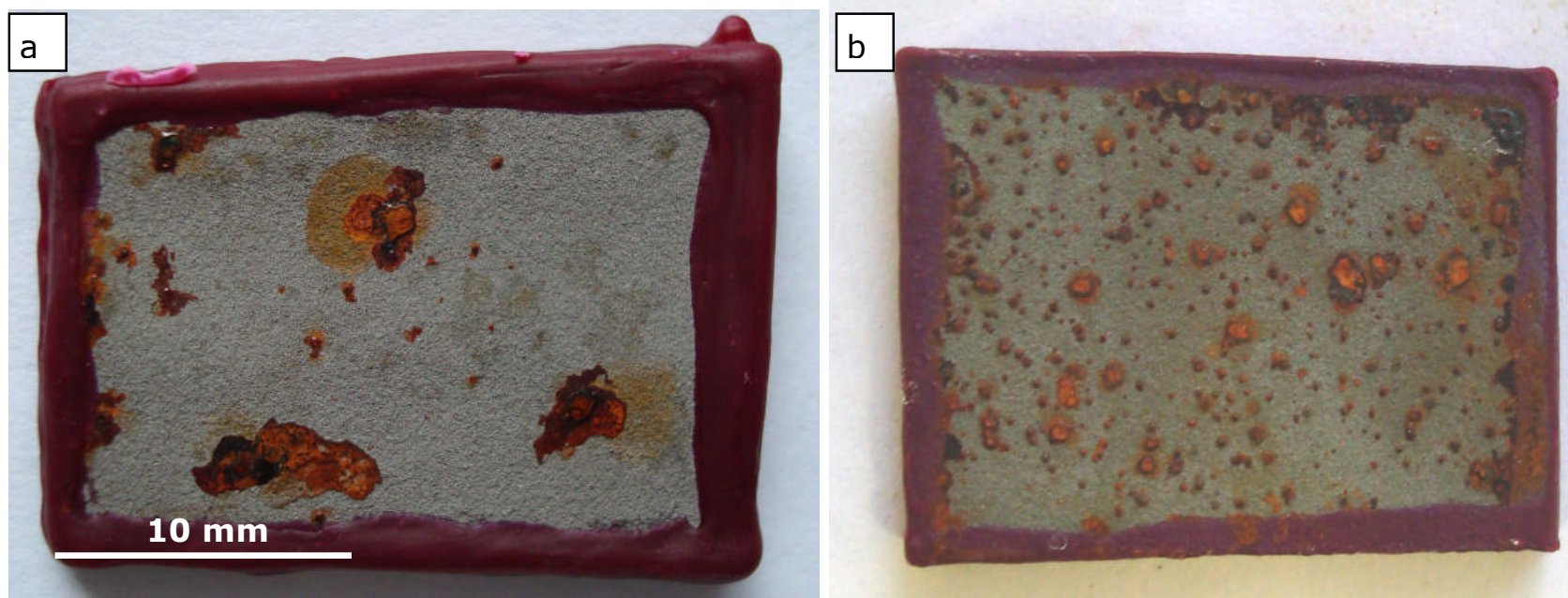

Figure 20 


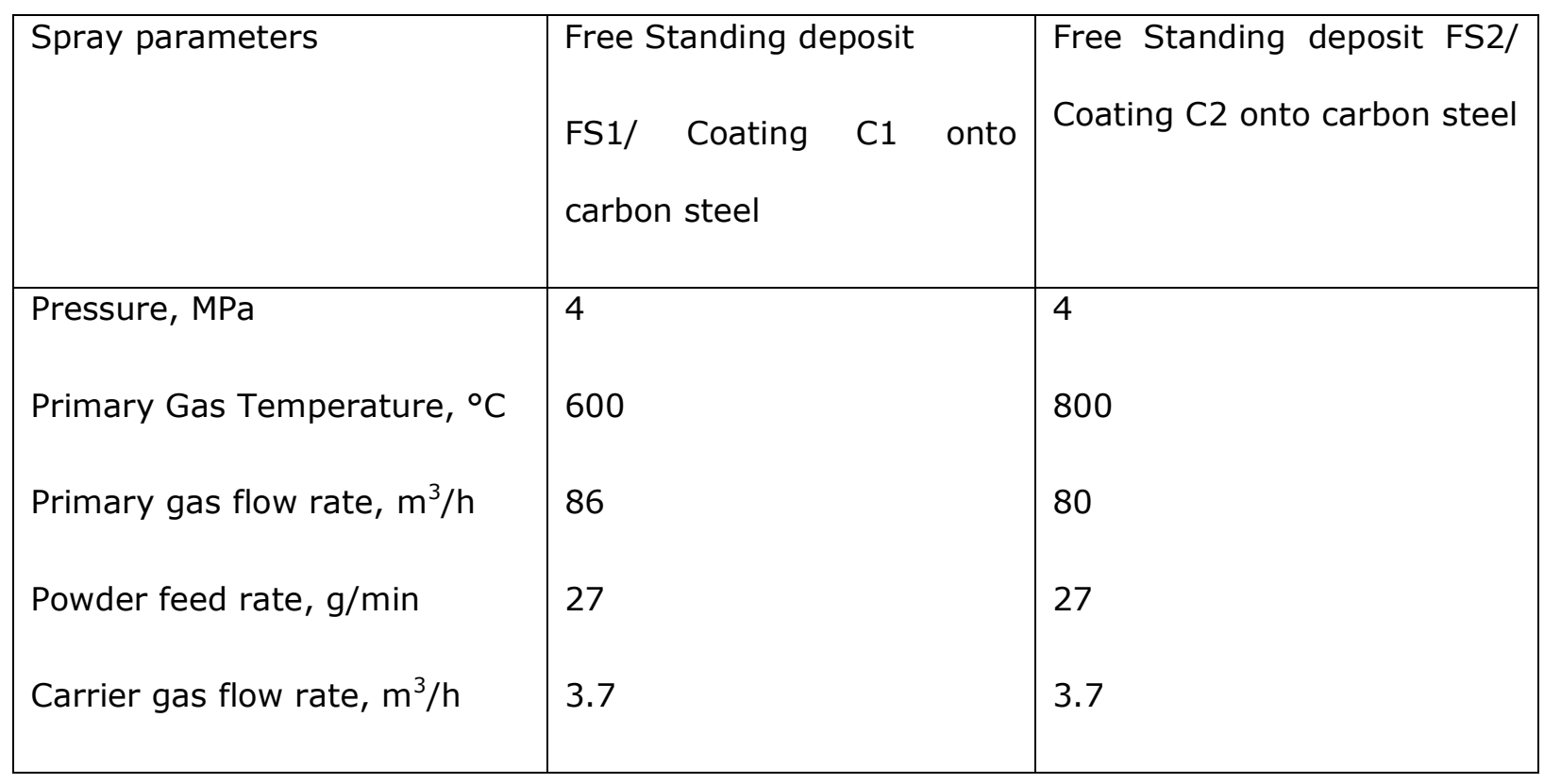

Table 4

\begin{tabular}{|c|c|c|c|c|}
\hline Process conditions & $\begin{array}{l}\text { Total intrusion } \\
(\mathrm{mL} / \mathrm{g})\end{array}$ & $\begin{array}{l}\text { Total volume } \\
\text { percentage of } \\
\text { interconnected } \\
\text { open porosity } \\
(\text { vol. \%) }\end{array}$ & $\begin{array}{l}\text { Volume } \\
\text { percentage of } \\
\text { porosity with } \\
\text { pore size > } 1 \\
\mu \mathrm{m}(\text { vol. } \%)\end{array}$ & $\begin{array}{l}\text { Volume } \\
\text { percentage of } \\
\text { porosity with } \\
\text { pore size < } 1 \\
\mu \mathrm{m}(\text { vol. \%) }\end{array}$ \\
\hline $\begin{array}{l}\text { As-sprayed } \quad \text { FS1 } \\
\text { deposit }\end{array}$ & 0.025 & 11.3 & 9.9 & 1.4 \\
\hline $\begin{array}{l}\text { Heat treated FS1 } \\
\text { deposit }\end{array}$ & 0.010 & 4.5 & 4.0 & 0.5 \\
\hline $\begin{array}{l}\text { As-sprayed } \quad \text { FS2 } \\
\text { deposit }\end{array}$ & 0.013 & 5.9 & 1.4 & 4.5 \\
\hline $\begin{array}{l}\text { Heat treated FS2 } \\
\text { deposit }\end{array}$ & 0.004 & 1.8 & 0.2 & 1.6 \\
\hline
\end{tabular}

Table 5 


\begin{tabular}{|c|c|c|c|c|}
\hline Specimens & $\begin{array}{l}\text { OCP after } 1 \\
\mathrm{hr} \quad \text { wrt } \\
\mathrm{Ag} / \mathrm{AgCl} \\
(\mathrm{mV})\end{array}$ & $\begin{array}{l}\text { Ecorr wrt } \\
\mathrm{Ag} / \mathrm{AgCl} \\
(\mathrm{mV})\end{array}$ & $\begin{array}{l}\text { Corrosion } \\
\text { current } \\
\text { density, Icorr } \\
\left(\mathrm{mA} / \mathrm{cm}^{2}\right)\end{array}$ & $\begin{array}{l}\text { Passive } \\
\text { current } \\
\text { density, Ipp } \\
\left(\mathrm{mA} / \mathrm{cm}^{2}\right)\end{array}$ \\
\hline Bulk titanium & -220 & -233 & $6.0 \times 10^{-5}$ & 0.005 \\
\hline As-sprayed FS1 deposit & -540 & -565 & $1.9 \times 10^{-3}$ & $0.017-0.13$ \\
\hline Heat treated FS1 deposit & -525 & -600 & $2.4 \times 10^{-5}$ & 0.007 \\
\hline As-sprayed FS2 deposit & -510 & -483 & $2.0 \times 10^{-4}$ & 0.005 \\
\hline Heat treated FS2 deposit & -365 & -373 & $3.0 \times 10^{-5}$ & 0.005 \\
\hline Carbon steel & -750 & -740 & $3.0 \times 10^{-3}$ & - \\
\hline C1 coating onto carbon steel & -700 & -836 & $3.5 \times 10^{-3}$ & 1.1 \\
\hline C2 coating onto carbon steel & -500 & -603 & $2.0 \times 10^{-3}$ & 0.7 \\
\hline
\end{tabular}

\section{Table 6}

